\title{
A Novel Switched Reluctance Motor with Permanent Magnets between the Stator Poles
}

\author{
K. Nakamura, K. Murota, and O. Ichinokura \\ Graduate School of Engineering, Tohoku University, 6-6-05 Aoba, Aramaki, Aoba-ku, Sendai 980-8579, Japan
}

\begin{abstract}
A switched reluctance (SR) motor has a doubly salient pole structure. It has some merits in comparison with other motors: simple structure, robustness, low cost, and capability for high-speed rotation. However, there are problems of torque ripple and acoustic noise. In addition, the power-to-weight ratio and efficiency need to be improved. Recent advances in power electronics technology allow meticulous current control to reduce the ripple and noise. On the other hand, the core material and motor structure must be further examined to improve the power-to-weight ratio and efficiency. This paper presents a novel SR motor with permanent magnets between the stator poles. The characteristics of the proposed motor are calculated by using a finite element method (FEM) and compared with those of conventional SR motors. The availability of the proposed SR motor is then clarified experimentally.
\end{abstract}

Key words: switched reluctance (SR) motor, permanent magnet, finite element method (FEM).

\section{固定子極間に永久磁石を有するスイッチトリラクタンスモータ \\ 中村健二・室田浩平・一ノ倉理 \\ 東北大学 大学院工学研究科, 仙台市青葉区荒巻字青葉 6-6-05（†980-8579）}

\section{1. はじめに}

近年，環境問題や省エネルギーに対する関心の高まりと共に， 環境にやさしく，かつ低燃費を実現した自動車の需要が伸びてい る.この中でも特に，電気自動車 $(\mathrm{EV})$ や，内燃機関とモータを 併用したハイブリッド自動車 (HEV) が注目されている。これら の駆動用モ一夕には, 要求される出力特性を満足するのと同時に, 車両への搭載性の面から小型・軽量であること, 電気エネルギー を高効率で動力に変換できること，運転時の振動や様々な温度条 件に対して信頼性が高く，か保守性に優れること，そして普及 のためには低コストであることが要求される. これらの要求を満 足するモータとして，スイッチトリラクタンス (SR) モータが注 目される.

SR モ一夕は，固定子，回転子ともに突極構造を有しており，磁 気回路の磁気抵抗变化に起因寸る，リラクタンストルクを利用し て回転するモータである 1), 2). 巻線は固定子極にのみ集中巻され， 回転子には巻線や永久磁石を必要としない. 従って, SR モ一タは 構造が極めて簡単で堅牢かつ安価，高速回転に適する，而熱性に 優れるなどの特長を有している. また，近年のパワーエレクトロ ニクス技術の進展により，モータのきめ細やかな制御が可能にな り，これまで指摘されていたトルクリプルや騒音などの問題につ いても改善が進んでいる ${ }^{3), 4)}$. 最近では, 洗濯機や掃除機などへの 実用化も始まっており, 今後は EVや HEV への応用も期待されて (る5)-7)

しかしながら， SR モータを EV や HEV に応用するためには， 解決す心゙き問題もある. そのひとつがモータの大トルク・高効率 化である. これらの問題を解決するため, 筆者らはSR モータの材 料や構造に関する検討を進めている8).

本稿では，固定子極間に永久磁石を配置することで，トルク， 効率の大幅な向上を実現した SR モータを提案し，有限要素法 (FEM)，並びに試作機を用いて諸特性の検討を行う.

\section{2. 固定子極間に磁石を有する SR モータの基本特性}

\section{1 提案するモータの基本構成}

Fig. 1 に, 本稿で提案する SR モ一夕の基本構成を示す. 固定子 極数 12 , 回転子極数 8 の 3 相 SR モ一夕の固定子極間には，それ ぞれ周方向に着磁された永久磁石が挿入されている. 図中の○は, 磁石の $\mathrm{N}$ 極を表している. また，矢印は固定子巻線による励磁の 方向を示しており, 磁石による磁束の流れとは逆方向になってい ることがわかる。

Fig. 2 の固定子極における動作磁束密度の変化を示した模式図 を用いて，提案する SR モ一タの基本動作を説明する. SR モータ は, 回転子に界磁巻線や永久磁石が無いため, 非励磁相の動作磁 束密度は, 同図(a)の原点にある。その後, 励磁開始とともに磁束 密度は増加するが, SR モー夕は一般にユニポーラ駆動されるため, 動作点は同図(a)の第 1 象限内に限定される. 一方, 提案する固定 子極間に磁石を挿入した SR モータの場合, 非励磁状態での動作磁 束密度は，同図(b)に示寸ように磁石によって負方向に逆バイアス される.これにより，鉄心の飽和磁束密度は見かけ上 $\left(B_{s}+B_{m}\right)$ となるため, 発生トルクの向上が期待される.

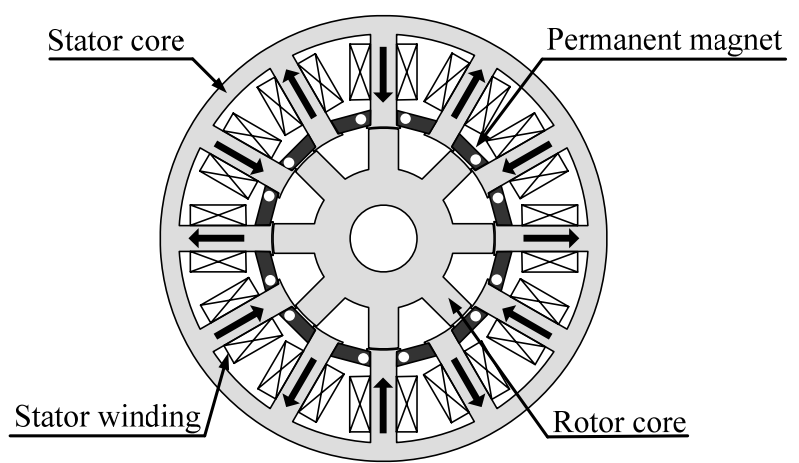

Fig. 1 A novel SR motor with permanent magnets between the stator poles. 


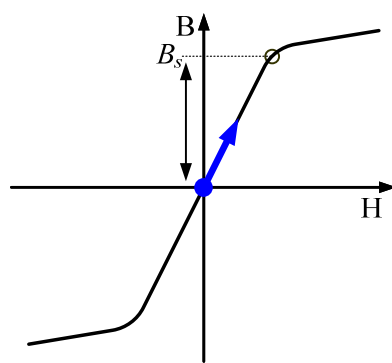

(a) Without magnets

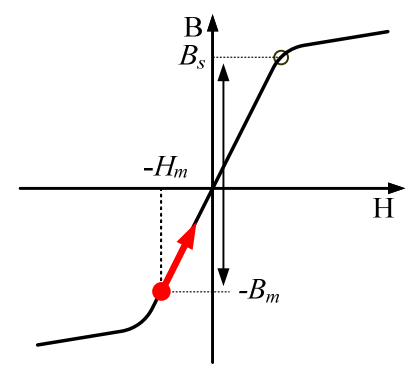

(b) With magnets
Fig. 2 Operating points of the stator pole of the SR motor with and without magnets.

\section{2 FEMによる特性算定}

本節では, FEM を用いて固定子極間に永久磁石を有する SR モ 一タの特性を算定する. 解析するモ一夕の直径は $160 \mathrm{~mm}$ ，積み 厚は $90 \mathrm{~mm}, 1$ 相当りの巻線数は 70 である. また, 直流電源電 圧は $176 \mathrm{~V}$, 定格出力は約 $10 \mathrm{~kW}$ である. Fig. 3 に, SR モータ の 2 次元 FEM モデルを示す. 紙面の都合上, モデルの空気領域, 巻線領域，およびシャフト領域は表示していない。永久磁石を挿 入した固定子極先端では, 磁束分布が複雑になることが予想され るため, メッシュをより細かく分割している．同図中の駆動回路 は FEM モデルと連成され，一定回転で駆動した場合のモ一夕特 性を算定することができる，なお，本稿では固定子極と回転子極 が対向した位置角を 0 deg. と定義する. 従って, 非対向になる位 置角は $\pm 22.5 \mathrm{deg}$.である.

Fig. 4 に, FEM で算定したSR モータの磁化曲線を示す. 同図 (a)が, 磁石が無い通常の SR モータの磁化曲線であり, 同図(b)が, 固定子極間に磁石を有する SR モータの磁化曲線である. 通常の SR モ一夕の場合, 磁化曲線は第1象限のみに現れる.これに対し, 提案する SR モ一夕の場合, 永久磁石による磁束の向きが, 巻線電 流による励磁の向きと逆であるため, 原点が第 4 象限側に大きく 逆バイアスされていることがわかる. 一方, 磁束が飽和寸る值は, 通常のSR モータとほぼ同じであるため, 対向位置 (0 deg.) と非 対向位置 (22.5 deg.) の磁化曲線で囲まれる, モ一夕の動作領域 は, 提案する SR モ一タの方が大きい. ここで, SR モ一タの発生 トルクは, 上述の動作領域に比例することから, 提案するモ一タ の方が，より大きなトルクを発生できることが推察される.

Fig. 5 に, FEM で算定したSR モータの静止トルク特性を示す. 実線が提案する SR モータのトルク特性であり, 破線が通常の SR モータのトルク特性である. この図を見ると, 対向位置に近付く,
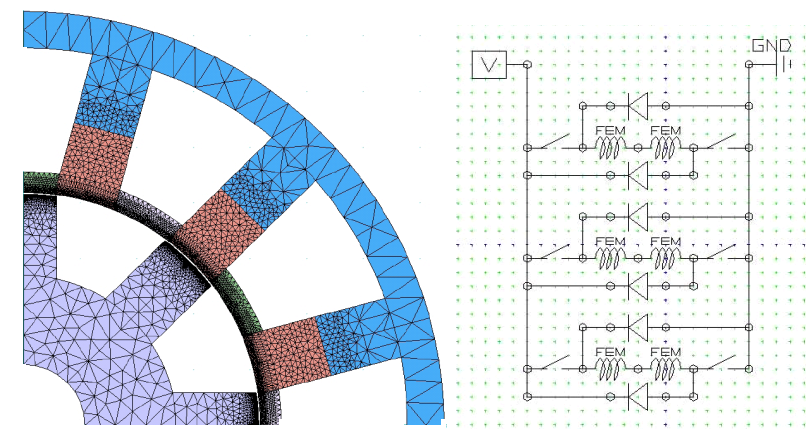

Fig. 3 FEM model and its driving circuit.
あるいは電流が大きくなり動作点が鉄心の飽和領域に近付くほど， 磁石によるトルク向上の効果が顕著に現れることが確認できる。

一方，永久磁石を固定子あるいは回転子に配置すると，これに 起因したコギングトルクの発生が眯念されるが, 提案するモータ の場合, 永久磁石の両極が固定子鉄心で短絡されるため, 磁石の 磁束は回転子に流れ込むことはほとんど無く, 従って Fig. 6 に示 すように，コギングトルクも発生しない.

Fig. 7 に, FEM で算定した電流密度特性を示す. 巻線の連続最 大電流密度を $13 \mathrm{~A} / \mathrm{mm}^{2}$ とした場合, 通常の $\mathrm{SR}$ モータでは最大卜 ルクが $39 \mathrm{~N} \cdot \mathrm{m}$ であるのに対し, 提案するモータでは, その約 1.4 倍に相当する $55 \mathrm{~N} \cdot \mathrm{m}$ と大幅に向上することがわかる.

Fig. 8に, 負荷トルクが $30 \mathrm{~N} \cdot \mathrm{m}$ の場合の巻線電流波形を示寸. 通常の SR モータでは, 鉄心の磁気飽和に起因寸る電流の鋭いピー クが認められる. 一方, 提案する SR モ一タの電流波形は緩やかで あり，動作点が末飽和領域にあることがわかる。

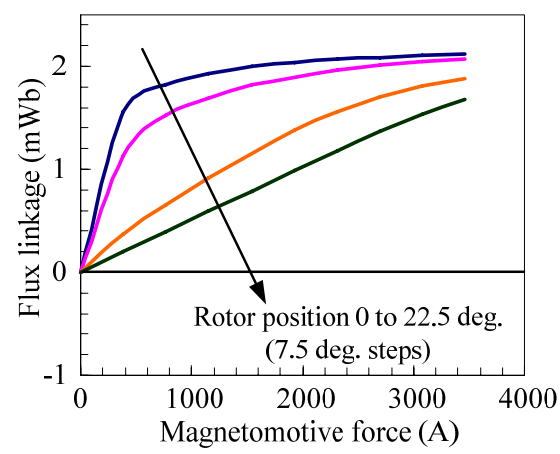

(a) Without magnets

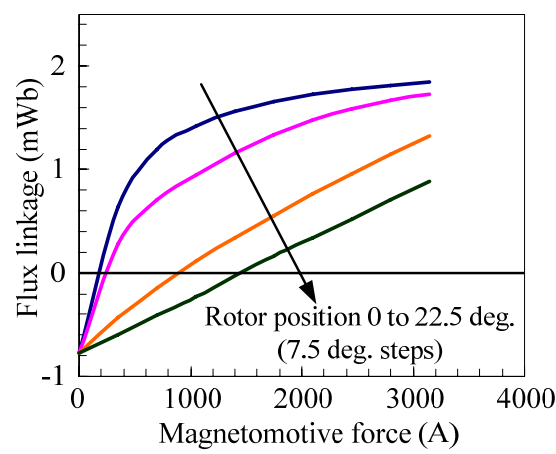

(b) With magnets

Fig. 4 Calculated flux-MMF curves of SR motors.

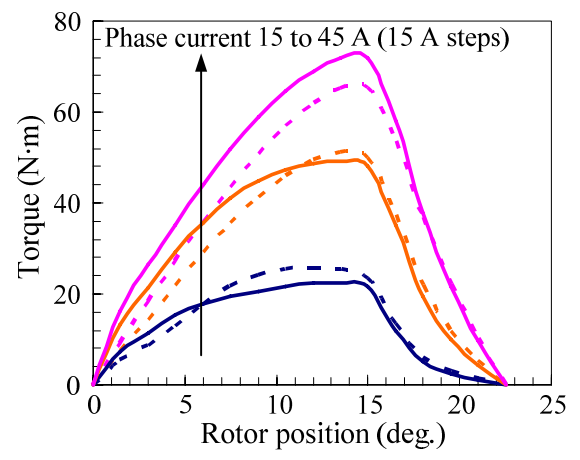

Fig. 5 Calculated static torque characteristics of SR motors (dotted lines: without magnets, lines: with magnets). 


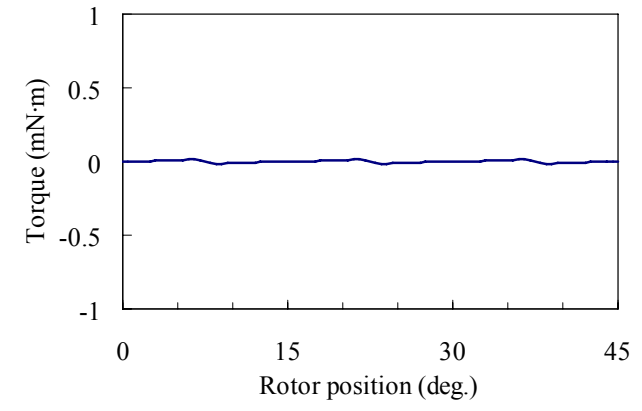

Fig. 6 Calculated cogging torque of the SR motor with permanent magnets.

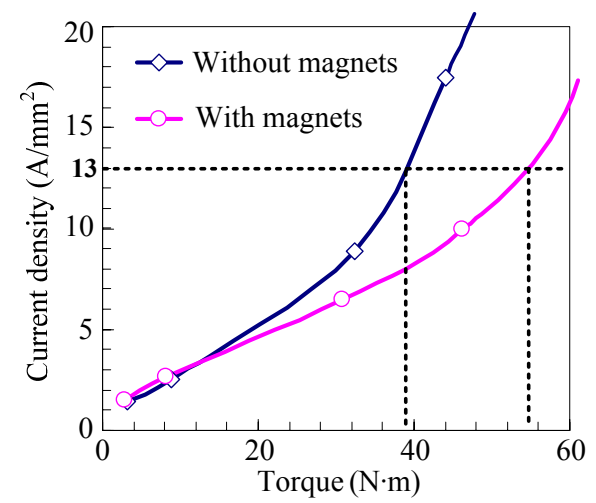

Fig. 7 Calculated current density characteristics.

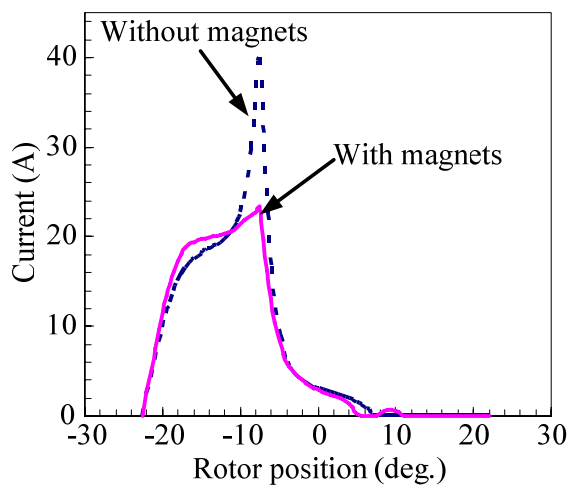

Fig. 8 Calculated waveforms of a winding current at $30 \mathrm{~N} \cdot \mathrm{m}$.

\section{3. 試作機による検証}

前章での検討により，固定子極間に永久磁石を挿入することで, $\mathrm{SR}$ モ一タの動作領域が拡大し, 発生トルクが大幅に向上すること が示された. 以下では, 試作した実機を用いて更に検討を進める.

Fig. 9 に, 試作機の構造と諸元を示寸.モ一タの直径は $118 \mathrm{~mm}$, 積夕厚は $40 \mathrm{~mm}$, ギャップ長は $0.3 \mathrm{~mm}$ である. 固定子, 回転子 の材料は厚さ $0.35 \mathrm{~mm}$ の無方向性電磁鋼板であり, 磁石材料は $\mathrm{Nd}-\mathrm{Fe}-\mathrm{B}$ である. なお, 実験装置の都合により, 試作したモータ の直流電源電圧は $100 \mathrm{~V}$, 定格出力は約 $500 \mathrm{~W}$ とした. また比較 のため，同形状，同寸法の通常のSR モ一タも製作した.

Fig. 10 に，負荷トルクを種々変えた場合の, SR モ一タの動作 点の軌跡を示す.この図を見ると, 通常の SR モータでは, 動作点 が第 1 象限内に限られるのに対して, 提案する SR モータでは, 動作点が第4象限側に逆バイアスされていることがわかる. また, 通常の SR モータでは, 負荷が $3 \mathrm{~N} \cdot \mathrm{m}$ に達寸ると, 動作点が飽和
の深い領域まで達し, 鋭いピークを示す. 一方, 提案する SR モー タでは, 動作点が未飽和領域にあることがわかる.

Fig. 11 に電流密度特性を示寸. 巻線の連続最大電流密度を 13 $\mathrm{A} / \mathrm{mm}^{2}$ とすると, それぞれの最大トルクは提案する $\mathrm{SR}$ モータが $4.8 \mathrm{~N} \cdot \mathrm{m}$, 通常の $\mathrm{SR}$ モータが $3.8 \mathrm{~N} \cdot \mathrm{m}$ となり, 最大トルクは約 $26 \%$ 向上した.

Fig. 12 に，負荷トルクを $3 \mathrm{~N} \cdot \mathrm{m}$ とした場合の巻線電流波形を 示寸. 同図(a)に示寸通常の SR モータでは, 電流波形に磁気飽和 に起因する鋭いピークが認められるが，同図(b)の提案するモ一夕 では, 動作点が未飽和領域にあるため, 電流にピークは現れない.

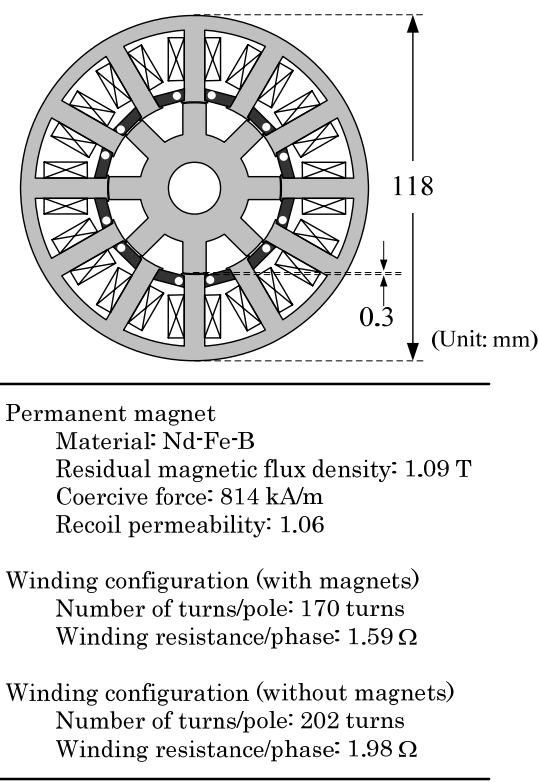

Fig. 9 Specifications of the trial SR motors.

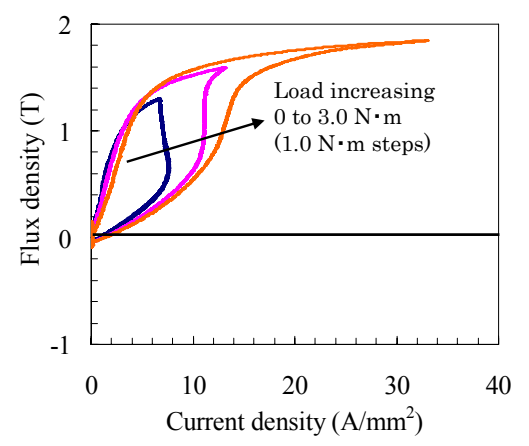

(a) Without magnets

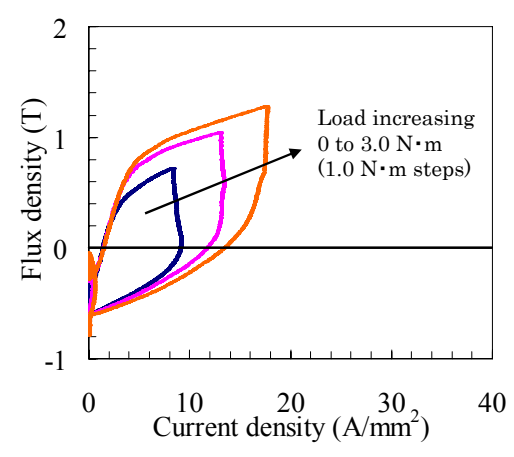

(b) With magnets

Fig. 10 Locus of the operating point for various torques. 


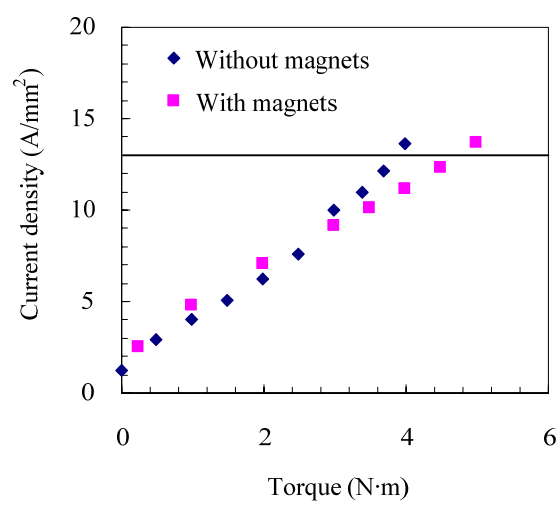

Fig. 11 Measured current density characteristics.

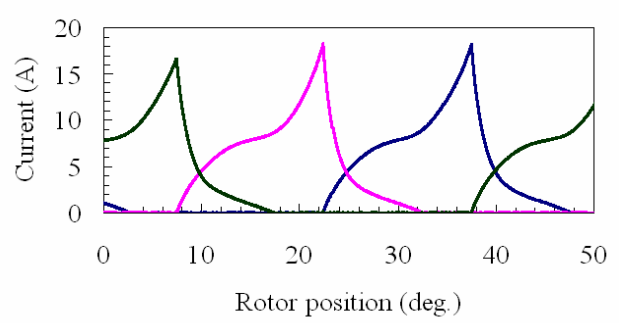

(a) Without magnets

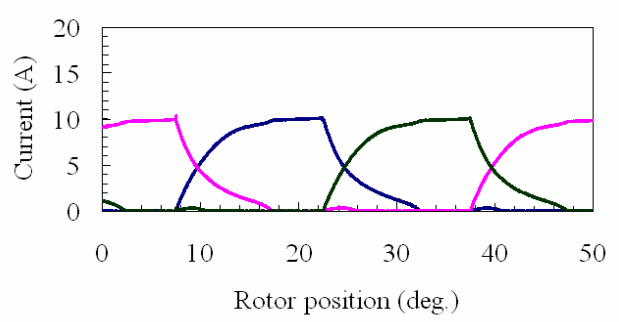

(b) With magnets

Fig. 12 Observed wave forms of winding currents at $3.0 \mathrm{~N} \cdot \mathrm{m}$.

Fig. 13 にトルク - 速度特性を示寸. SR モータの回転速度はト ルクの平方根に反比例して減少する, いわゆる直巻特性を示すが, 通常の $\mathrm{SR}$ モータでは， $3 \mathrm{~N} \cdot \mathrm{m}$ を超えると過負荷になり，この直 巻特性から外れ, 速度が大きく減少する様子が認められる. 一方, 提案するモータでは, 現有する測定装置の限界である $5 \mathrm{~N} \cdot \mathrm{m}$ まで, 直巻特性を示しており, 特性が著しく改善されていることがわか る.

Fig. 14 に効率特性を示寸. この図を見ると, $2 \mathrm{~N} \cdot \mathrm{m}$ 以下の軽負 荷では，両者に差は認められない，一方， $2 \mathrm{~N} \cdot \mathrm{m}$ 以上の重負荷領 域に入ると, 通常の SR モータでは急激に効率が減少するのに対し て，提案するモータではその減少が非常に緩やかであることがわ かる. これは, Fig. 11 に示した電流波形からもわかるように，通 常のSR モータでは, 重負荷領域に入ると鉄心が飽和して大きな電 流が流れるのに対して，提案寸るモ一タでは電流が低く抑えられ るため，銅損が減少したことが効率の大幅な改善につながったと 考えられる.

\section{4. まとめ}

以上，固定子極間に永久磁石を配置することで，トルク，効率 の大幅な向上を実現した SR モータについて述べた. まず，有限要素法 (FEM) を用いて，提案する SR モータの動

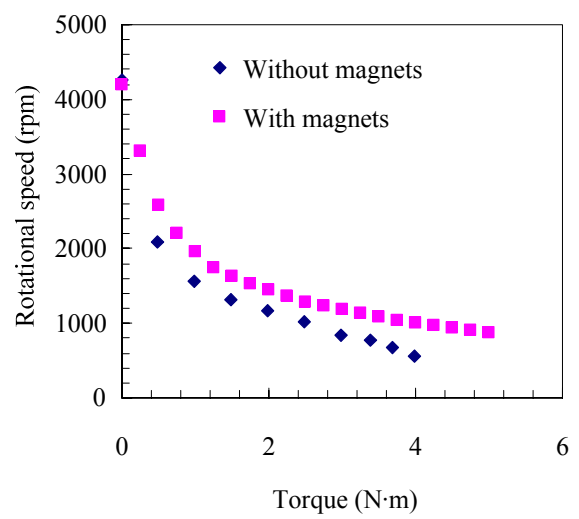

Fig. 13 Measured rotational speed characteristics.

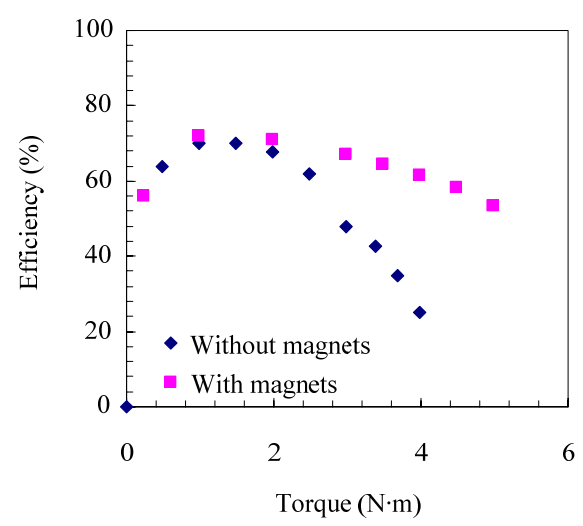

Fig. 14 Measured efficiency characteristics.

作領域が，永久磁石の逆バイアス効果により，従来の第 1 象限の みから, 第 4 象限を含む領域まで拡大寸ることを示した. 動作領 域の拡大は, SR モ一タのトルク向上に寄与する. また, トルク向 上の効果は，動作点が鉄心の飽和領域に近付くほど大きい.

次いで，試作機による検証を行い，固定子極間に永久磁石を有 する SR モ一夕は, 通常の SR モ一タと比較して, $20 \%$ 以上最大 トルクが向上することを示した. また, 重負荷領域で効率が著し く改善されることを示した.

今後は，固定子極間に挿入する磁石の最適設計を行い，更なる 特性の向上を目指寸予定である.

\section{References}

1) R. C. Becerra, M. Ehsani, and T. J. E. Miller, IEEE Trans. Power Electron., 8, 257 (1993).

2) N. Matsui and Y. Takeda, T. IEE Japan, 118-D, 685 (1998) [in Japanese].

3) S. Mir, M. E. Elbuluk, and I. Husain, IEEE Trans. Ind. Applicat., 35, 461 (1999).

4) K. M. Rahman and S. E. Schulz, IEEE Trans. Ind. Applicat., 38, 1062 (2002).

5) Y. Akiyama and T. Kuroda, The Papers of Technical Meeting on Rotating Machinery, IEE Japan, RM-99-28 (1999) [in Japanese].

6) S. S. Ramamurthy and J. C. Balda, IEEE Trans. Ind. Applicat., 37, 1256 (2001).

7) K. Nakamura, Y. Suzuki, H. Goto, and O. Ichinokura, Journal of Magnetism and Magnetic Materials, 290-291, 1334 (2005).

8) K. Nakamura, T. Ono, H. Goto, T. Watanabe, and O. Ichinokura, IEEE Trans. Magn., 41, 3919 (2005).

\section{6年10月3日受理，2007年1月23日採録}

